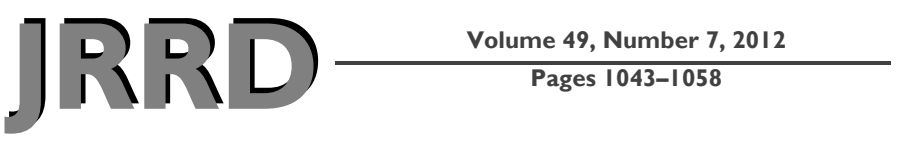

\title{
Blast exposure and dual sensory impairment: An evidence review and integrated rehabilitation approach
}

\author{
Gabrielle H. Saunders, PhD; ${ }^{*}$ Katharina V. Echt, $\mathbf{P h D}^{\mathbf{2}}$ \\ ${ }^{1}$ National Center for Rehabilitative Auditory Research, Department of Veterans Affairs (VA) Rehabilitation Research \\ and Development Service, Portland VA Medical Center, Portland, OR; and Department of Otolaryngology, Head, and \\ Neck Surgery, Oregon Health and Science University, Portland, OR; ${ }^{2}$ Rehabilitation Research and Development Cen- \\ ter of Excellence and Geriatric Research, Education and Clinical Center, Atlanta VA Medical Center, Decatur, GA; and \\ Division of Geriatric Medicine and Gerontology, Department of Medicine, Emory University School of Medicine, \\ Atlanta, GA
}

\begin{abstract}
Combat exposures to blast can result in both peripheral damage to the ears and eyes and central damage to the auditory and visual processing areas in the brain. The functional effects of the latter include visual, auditory, and cognitive processing difficulties that manifest as deficits in attention, memory, and problem solving-symptoms similar to those seen in individuals with visual and auditory processing disorders. Coexisting damage to the auditory and visual system is referred to as dual sensory impairment (DSI). The number of Operation Iraqi Freedom/Operation Enduring Freedom Veterans with DSI is vast; yet currently no established models or guidelines exist for assessment, rehabilitation, or service-delivery practice. In this article, we review the current state of knowledge regarding blast exposure and DSI and outline the many unknowns in this area. Further, we propose a model for clinical assessment and rehabilitation of blast-related DSI that includes development of a coordinated team-based approach to target activity limitations and participation restrictions in order to enhance reintegration, recovery, and quality of life.
\end{abstract}

Key words: auditory training, blast exposure, blast injury, central auditory processing disorder, dual sensory impairment, rehabilitation, traumatic brain injury, veteran, visual processing disorder, visual training.

\section{INTRODUCTION}

Rehabilitation research on dual sensory impairment (DSI) is fairly sparse and has primarily focused on deafblind individuals [1] or aging individuals with gradual onset peripheral hearing loss and vision loss (see Saunders and Echt [2]). Little or no research has been conducted to examine the effect of, and rehabilitation for, DSI associated with military operations. Combat exposures can result in both peripheral damage to end organs

\footnotetext{
Abbreviations: $\mathrm{AV}=$ audiovisual, $\mathrm{CI}=$ confidence interval, DSI = dual sensory impairment, ERP = event-related potential, $\mathrm{FM}$ = frequency modulation, $\mathrm{HI}=$ hearing impairment, $\mathrm{HL}=$ hearing level, NSI = no sensory impairment, OIF/OEF = Operation Iraqi Freedom/Operation Enduring Freedom, PTSD = posttraumatic stress disorder, TBI = traumatic brain injury, VA = Department of Veterans Affairs, VHA = Veterans Health Administration, VI = visual impairment, WHO-DAS II = World Health Organization Disability Assessment Schedule II.

*Address all correspondence to Gabrielle H. Saunders, PhD; VA RR\&D National Center for Rehabilitative Auditory Research (NCRAR), Portland VAMC, 3710 SW U.S. Veterans Hospital Rd, Portland, OR 97239; 503-220-8262; fax: 503-721-1402.

Email: gabrielle.saunders@va.gov

http://dx.doi.org/10.1682/JRRD.2010.08.0157
} 
(ears and eyes) and in central damage to the auditory and visual processing areas in the brain. Hearing protection, eye protection, Kevlar helmets, and body armor have considerably decreased the occurrence of peripheral injuries [3]; however, a current major concern is damage to the central auditory and visual systems resulting from blast exposure [4-5], which can cause sensory processing deficits that broadly manifest as difficulties understanding speech and difficulties reading [6-7]. More specifically, auditory complaints include difficulty listening in the presence of background noise, following oral instructions, and understanding rapid or degraded speech [8]. Visual complaints pertinent to reading include difficulties with blur, text navigation and search, fluency and reading speed, sustained reading, and reading comprehension [9]. In many cases, individuals with these auditory and visual difficulties have clinically normal or almost normal hearing and visual acuity [10].

Vast numbers of servicemembers have returned from Operation Iraqi Freedom/Operation Enduring Freedom (OIF/OEF) with blast-related injuries [11], such that blast-related mild traumatic brain injury (TBI) has been referred to as the "signature wound" of the current conflicts [12]. There are four different mechanisms through which blast injuries arise: primary, secondary, tertiary, and quaternary. Primary blast injuries are caused by the over- and underpressurization of air generated by the blast itself; secondary injuries are caused by flying debris; tertiary injuries result from the body being thrown by the blast wave; and quaternary injuries are associated with factors such as inhalation of toxic fumes, burns, and crush injuries [13]. Although the brain is vulnerable to primary, secondary, and tertiary injuries, for the purpose of this review we are interested in the damage from primary injuries, which, as shown by magnetic resonance imaging, cause diffuse axonal injury, contusions, and subdural hemorrhage [14]. Diffuse axonal injury results when axons are sheared or stretched, contusions occur when the brain moves within the skull to cause bruising of the brain parenchyma, and subdural hemorrhage occurs when the movement of the brain in the skull is sufficient to tear the surface veins. Diffuse axonal injury is seen most commonly in the corticomedullary junction, the internal capsule, and the upper brain stem and corpus callosum. Contusions are most common in the inferior, lateral, and anterior frontal and temporal lobes, and hemorrhaging is seen in the frontal and parietal convexities [14]. The functional effects of these blast effects include visual, auditory, and cognitive processing difficulties that manifest as deficits in attention, memory, and problem solving-symptoms similar to those seen in individuals with visual and auditory processing disorders [15].

In this article, we review the current state of knowledge regarding blast exposure and DSI and also outline the many unknowns regarding assessment, rehabilitation, and clinical service models for addressing blast-related DSI.

\section{METHODS}

We conducted a literature review of published peerreviewed empirical studies and reviews using "vision" or "visual" and/or "hearing” or "auditory," "sensory," and "dual sensory" as primary search terms, coupled with "loss," "impairment," "dysfunction," "processing disorder," "training," "rehabilitation,” "traumatic brain injury,” "blast," "blast exposure," and "blast injury" as search terms in PsychInfo, Medline, Cochrane Database of Systematic Reviews, and Google Scholar. We focused identified selections to the objective of describing what is known about blast exposure and DSI, as well as identifying gaps in knowledge, to provide a synthesized content review of (1) the effects of blast exposure on the auditory and visual systems; (2) the prevalence and effects of DSI; and (3) the implications for definition, assessment, and rehabilitation practice.

\section{RESULTS AND DISCUSSION}

\section{Damage to Auditory System}

Unlike the typical sensorineural hearing loss that comes about from long-term exposure to high-intensity noise, blasts cause conductive, mixed, and sensorineural hearing losses arising from the sudden and vast change in air pressure $[4,16]$. Specifically, blasts can rupture the tympanic membrane, damage the ossicular chain, tear inner and outer hair cells away from the support cells, and rupture the reticular laminar in the cochlea [17]. These injuries and their associated effects on hearing and communication are relatively well understood, and routine rehabilitation, such as surgery for ossicular damage and provision of amplification for sensorineural hearing loss, can be offered. While amplification is far from being a perfect solution to cochlear damage, at least the 
shortcomings and benefits of hearing aids and other assistive devices are recognized.

Of greater concern, perhaps, are the many OIF/OEF Veterans reporting hearing difficulties in the absence of conventionally defined hearing loss. The number of individuals with these complaints is unknown; however, studies suggest the numbers are substantial. In 2007, Lew et al. noted that 26 of 42 individuals with a blast-related TBI reported hearing difficulties but that 11 percent of the 26 had normal pure-tone sensitivity [18]. More recent data suggest the numbers may be considerably higher [19]. Specifically, it was determined that 65.9 percent of 12,521 Veterans judged to have deployment-related TBI and who reported being exposed to blast complained of auditory difficulties. Although the audiometric status of these individuals was not stated, we can estimate from other studies that between 35 and 54 percent had permanent sensorineural hearing loss [17-18,20] and a further 7 percent had ruptured tympanic membranes [3], suggesting that about 20 percent of those reporting hearing difficulties had normal or almost-normal audiometric thresholds. Saunders and Abrams suggested that clinicians note an equally high number of Veterans who perceive hearing difficulties and yet have normal or almost normal auditory acuity [21]. Saunders and Abrams conducted a survey of Department of Veterans Affairs (VA) audiologists to determine how often they encounter OIF/ OEF Veterans who complain of difficulties hearing and yet have normal or almost-normal pure-tone sensitivity. Of the VA audiologists, 92 percent reported encountering at least one such individual per month in their clinic, with 53 percent encountering between one and three per month and 39 percent encountering four or more per month.

Recent data from a study comparing blast-exposed servicemembers with a control group of non-blastexposed Veterans matched on age, sex, and degree of hearing impairment (HI) on a variety of auditory measures suggest that these reports of hearing difficulties in the presence of normal or near-normal hearing sensitivity are a result of damage to the central auditory system [22]. Specifically, the blast-exposed servicemembers performed more poorly than the controls on three measures of central auditory function: the Staggered Spondaic Word Test, the Gaps-in-Noise test, and masking level differences. They also found reduced P300 amplitudes and increased P300 latencies to an infrequently presented ( $20 \%$ of trials) $1,000 \mathrm{~Hz}$ target tone in an "oddball” paradigm among the blast-exposed servicemembers, whereas auditory brainstem responses and earlier components of the wave form (e.g., N100 peak and N1-P2 peak-totrough values) did not differ between the groups. This reflects normal function between the auditory nerve and brainstem but some degree of deficit for the attentiondriven P300 wave. Indeed, each of the measures differentiating the blast-exposed servicemembers from the nonblast-exposed controls likely reflects lesions in central cortical areas of the brain, many of which are associated with temporal processing. Gallun et al. hypothesized that damage to the fragile neural connections is associated with pressure differentials occurring in the brain as the blast wave passes through [22]. Similar findings of temporal processing deficits among individuals with nonblast-related TBI have been reported. Specifically, Bamiou et al. compared the auditory processing abilities of eight insular stoke patients with eight neurologically normal controls [23]. Each of the stroke patients showed deficits in temporal resolution and sequencing, while the controls performed at normal levels. Likewise, Griffiths et al. reported that following stroke, a patient reported he could no longer recognize familiar tunes unless they comprised long, slow notes [24]. Psychophysical testing revealed that the patient performed more poorly than nondisabled controls when the tones were played rapidly but that he performed similarly to the controls when the presentation rate was slow. Similarly, the patient was unable to conduct a binaural sound movement task. On the other hand, the patient's performance did not differ from that of controls on tests of pure-tone sensitivity and frequency modulation (FM) detection. Data from other non-Veterans with TBI show auditory deficits on other behavioral auditory tests. Paré et al. showed patients with mild TBI to have auditory working memory deficits as demonstrated by poorer digit span performance than nondisabled controls immediately after their injury and at 3month follow-up [25]. Kwok et al. reported that patients with a mild TBI performed more poorly than nondisabled controls immediately after injury and at 1-month followup on neuropsychological tests that included measures of both auditory and visual information processing (i.e., divided attention assessed with the Symbol Digit Modalities Test, sustained attention assessed with the Digit Vigilance Test, verbal recognition assessed with the Chinese Auditory Verbal Learning Test, and verbal fluency assessed with the Verbal Fluency Test) [26]. These individuals also had poorer sustained attention immediately after injury and at 1- and 3-month follow-ups. 
Like Gallun et al. [22], other studies have revealed electrophysiological abnormalities accompanying TBI among Veterans [27] and non-Veterans alike [28-29]. More specifically, Lew et al. found that patients with TBI had significantly lower P300 amplitude and longer P300 latencies for auditory event-related potentials (ERPs) than non-TBI controls [27], and Segalowitz et al. found university students with mild TBI to have lower P300 amplitudes and latencies on oddball vigilance task ERPs [28], while Gaetz and Weinberg reported that patients with persistent postconcussive syndrome had delayed P300 to both visual and auditory stimuli [29].

\section{Damage to Visual System}

A substantial percentage of OIF/OEF servicemembers exposed to blast that did not sustain overt ocular trauma self-report visual difficulties despite good eye health and visual acuity [5,7,30-31]. Akin to the effects of blast exposure on the auditory system, the visual pathways, cranial nerves, and other neurologic substrates responsible for visual function may also sustain damage consequent to blast $[7,9,14]$. Visual abnormalities detected in servicemembers with closed-head primary blast-injury most commonly include photosensitivity, oculomotor (i.e., version, vergence, accommodation) dysfunctions, and visual field losses [7,9]. Additional deficits, perhaps more subtle in their presentation, have been documented and include decrements in spatial contrast sensitivity, color discrimination [7], reduced speed and accuracy of scanning [32], spatial perceptual deficits [9], and impaired visual processing speed and attention [33]. The potential effects of blast-related TBI on vision are multiple, consistent with the diffuse injury affected across visual system structures, and variable across individuals and blast-exposures [34].

The deficits in visual function described may adversely affect performance of activities of daily living such as mobility and reading, which in turn limit engagement in education, vocation, and leisure. Slowed visual processing and reaction times, visual field losses, visualspatial perceptual and attention deficits, particularly in visually complex environments, may challenge safe ambulation (e.g., bumping into objects and/or people) and driving $[33,35]$. Reports indicate the most prevalent visual complaint of blast-injured Veterans is difficulty reading [36-37], particularly reading continuous text [7]. Difficulties that challenge reading ability include blurred vision, double vision, visual discomfort or fatigue, skip- ping words or lines of text, reduced reading speed, inefficient search for critical information, difficulty with sustained reading, and deficient reading comprehension $[34,36]$. In a sample of 125 Polytrauma Network Site outpatient Veterans, 63 percent reported difficulty with reading [36]. Stelmack et al. indicated that a reading problem was identified during the eye examinations of 18 out of 36 TBI clinic Veteran patients; however, average visual acuity was equivalent to 20/20 [37].

The centrality of visual acuity to definitions of visual function and visual impairment (VI) may limit the routine clinical detection of visual deficits in blast-exposed patients with normal or near-normal visual acuities [3839]. As part of a recent national survey of approximately 440 VA optometrists, we sought to determine how often these eye clinic providers encounter OIF/OEF Veterans who present with visual difficulties but who demonstrate normal or almost-normal visual acuities. The majority of the respondents reported encountering such patients on a monthly basis. Of VA optometrists, 83 percent reported seeing at least one or more such patients per month in their clinic, with 63 percent seeing one to three per month and 20 percent seeing more than four each month. The extent to which Veterans' visual difficulties consequent to blast-exposure are under-reported or unrecognized is not known [7].

Singly or in combination, the visual efficiency and visual processing deficits described adversely affect safety, independence, work, education, and quality of life. Importantly, visual deficits and dysfunctions do not exist in isolation, but coexist alongside a number of frequently associated comorbidities (e.g., posttraumatic stress disorder [PTSD], depression [37]) and injuries including cognitive effects. For instance, taken together, limitations in visual efficiency and visuocognitive information processing compound effects of blast on everyday function as is evident in mobility, reading, and reading comprehension difficulties [7,33-34,37]. Several reports, moreover, stress that unaddressed vision problems in this population may impede individual rehabilitation progress generally and particularly to the extent that aspects of rehabilitation are visually dependent $[34,36]$.

\section{Dual Sensory Impairment}

\section{Prevalence}

Studies examining the prevalence of DSI in the general population estimate that between 7 and 21 percent of 
adults has some degree of DSI [40-43], with the varying prevalence depending on the population and age group investigated. We are aware of only one published study that estimates the prevalence of DSI among the Veteran population to be in the range of 5.0 to 7.4 percent [44]. Smith et al. reported the prevalence of DSI among individuals aged 44 to 64 years old to be 0 percent (confidence interval [CI]: $0 \%-3.6 \%$ ), increasing to 26 percent (CI: $17.4 \%-34.6 \%$ ) for individuals over 85 years old. This study was based on a retrospective chart review of 400 randomly selected charts of Veterans receiving healthcare at the Mountain Home VA Medical Center (Mountain Home, Tennessee) and likely reflects agerelated $\mathrm{HI}$ and VI. The prevalence of DSI among blastinjured OIF/OEF Veterans is unknown, although a recent study has shed some light on the matter. Lew et al. conducted a retrospective chart review of 175 OIF/OEF Veterans with TBI who had been admitted to a Polytrauma Rehabilitation Center [45]. They documented four subgroups of patients based on the presence or absence of $\mathrm{HI}$ and VI: HI alone, VI alone, HI and VI (DSI), and no sensory impairment (NSI). HI was defined as being present if the patient had one or more thresholds of $26 \mathrm{~dB}$ hearing level (HL) or poorer at any octave frequencies between $250 \mathrm{~Hz}$ and $8 \mathrm{kHz}$. VI was defined based on acuity of worse than 20/63 in the better eye or with hemianopsia of $\leq 20^{\circ}$. Of the 175 charts reviewed, 62 patients had completed both hearing and vision evaluations from which the presence or absence of sensory impairments could be identified. Of these 62 patients, 12 (19\%) had HI alone, 21 (34\%) had VI alone, 9 (15\%) had NSI, and 20 (32\%) had DSI defined using the clinical metrics just described. Of particular interest, however, are those many individuals with blast-related injuries who report hearing and vision difficulties encountered by VA audiologists and optometrists and yet do not have measured impairmentat least when conventional clinical assessment procedures are used. These numbers are unknown. Lew et al. determined that of 12,521 Veterans reporting blast exposure and judged to have TBI, 34.6 percent reported both auditory and visual difficulties and only 24.2 percent reported neither auditory nor visual difficulties [19]. Lew et al. reported that 11 percent of blast-exposed Veterans and 4 percent of non-blast-exposed Veterans reported hearing loss but had no measureable impairment [18], and Brahm et al. found that 75.9 percent of blast-exposed and 75.0 percent of non-blast-exposed Polytrauma Network Site outpatients with mild TBI reported visual com- plaints, but 98.2 and 100.0 percent, respectively, had visual acuity of 20/60 or better [46]. These findings indicate that reports of hearing and vision dysfunction in the presence of peripherally normal or almost-normal hearing and vision are quite common.

\section{Effect}

Studies comparing single sensory impairment versus DSI have historically focused on older samples of individuals, and thus the extent to which these inquiries are applicable to the younger population of blast-exposed Veterans is not known. However, examination of the effect of DSI on other patient groups with differing etiologies may serve to guide future research directions specific to DSI in younger blast-exposed Veterans. Studies of older populations have shown that individuals with DSI report poorer health, greater activity limitations, less social participation, more depression, and greater cognitive and functional decline than those with a single sensory impairment or NSI. For example, Crews and Campbell examined questionnaire data of 9,447 individuals obtained during the 1994 Second Supplement on Aging study [47]. The presence of HI was ascertained by a positive response to one of the following items: "deafness in one ear," "deafness in both ears," or "any other trouble hearing;" VI was determined through a positive response to the item "trouble seeing even with glasses.” In this study, 58.0 percent of individuals reported NSI, 24.4 percent reported HI alone, 9.4 percent reported VI alone, and 8.2 percent reported DSI. Compared with individuals with NSI, those with HI were 1.7 times more likely to have fallen in the last 12 months, those with VI were 1.8 times more likely to have fallen, and those with DSI were 3.0 times more likely to have fallen. Similar statistics exist for the probability of reporting confusion (HI: 1.4, VI: 2.2, DSI: 2.8), difficulty bathing (HI: 1.4, VI: 2.8, DSI: 3.8), difficulty dressing (HI: 1.5, VI: 2.1, DSI: 3.6), difficulty preparing meals (HI: 1.5, VI: 3.5, DSI: 4.7), and difficulty using a telephone (HI: 3.6, VI: 4.9, DSI: 9.1). Interestingly, the contrasts between groups were not as great for socially based activities. For example, 73.9 percent of individuals with NSI reported visiting friends, while the numbers were 70.9 percent for those with HI, 66.8 percent for those with VI, and 63.4 percent for those with DSI. Similar numbers existed for telephoning friends (NSI: 83.9\%, HI: 75.7\%, VI: 79.8\%, DSI: $72.1 \%$ ), going to movies (NSI: $30.7 \%$, HI: 25.8\%, VI: $21.1 \%$, DSI: $19.5 \%$ ), and eating out (NSI: 66.0\%, HI: 65.9\%, VI: 56.3\%, DSI: 55.8\%). Likewise, 
Raina et al. examined data of 16,613 individuals older than 66 years who completed the 1991 Health and Activity Limitation Survey [48]. The data showed that individuals with DSI reported the most restrictions conducting instrumental activities of daily living (e.g., shopping, housework, personal care, meal preparation), followed by those with VI alone and then those with HI alone. Those with more severe sensory disabilities were more likely to report restrictions in ability to conduct instrumental activities of daily living and were less likely to have decision-making control and to be happy with their lives. Increased rates of depression with DSI have also been documented. Chou and Chi reported that individuals with DSI were 2.21 times more likely to be depressed than individuals with NSI [49]. The rates for single sensory impairment were 1.49 and 2.05 for HI alone and VI alone, respectively. Chia et al. conducted a study of the effects of DSI that differ from those described earlier, because rather than relying on self-reports of DSI, they assessed hearing and vision using clinical test procedures [50]. They examined 2,015 individuals aged 55 to 98 years from the Blue Mountains Eye Study at year 5 of longitudinal study participation. Of these, air and bone conduction thresholds at octave frequencies from 0.25 to $8 \mathrm{kHz}$ and monocular distance LogMAR visual acuity and cataract examinations were available from 1,836 participants. Participants also completed the Australian-adapted version of the 36-item Short Form Health Survey [46]. Of the participants, 40 percent had $\mathrm{HI}$ alone (pure tone average $>25 \mathrm{~dB} \mathrm{HL}$ ), 9.3 percent had VI alone (acuity $>20 / 40$ ), and 6 percent had DSI. They found that the individuals with DSI had significantly poorer physical function, general health perceptions, vitality, and mental and social well-being than individuals with a single sensory impairment or NSI.

These studies illustrate that the effects of DSI generally exceed the effects of single sensory impairment, presumably because the individual with DSI cannot compensate for the single sensory impairment with the second sense [2]. For example, it has been long established that supplementing a degraded auditory signal with visual information results in considerable benefit for speech understanding [51-52], resulting in improvements in speech understanding of 50 percent over auditoryalone conditions [53]. The explanation lies in the complementary nature of the information available from the auditory and visual signals [54-55]. Walden et al. also showed that such complementarities apply to benefit obtained from amplification, such that visual cues pro- vide place-of-articulation information, while amplification provides place, manner, and voicing cues [56]. Individuals with DSI are at a further disadvantage for understanding speech in that subtle, nonverbal cues, such as gestures, facial expressions, and body posture, are also lost. For instance, tone of voice provides information about mood and intent, facial expressions and posture can reveal the emotions of the speaker, gestures often provide information that supplement the verbal content, and eye contact provides an emotional link between the speaker and the listener. Consequently, while the literal content of the speech may be understood, the subtle paralinguistic information that enhances communication may be lost.

The interrelationships between the auditory and visual systems are not limited to lipreading. There is considerable evidence of overlap, both neuroanatomically and functionally. For instance, Cappe and Barone showed that in primates, the core of the auditory cortex receives direct inputs from both somatosensory and visual areas [57], while Wang et al. report that single neurons from a primary sensory cortex measured in a monkey can integrate visual sensory information [58]. From a functional standpoint, Recanzone demonstrated that spatial perception of the location of an auditory signal can be altered by providing a visually mismatched cue simultaneous with the auditory cue [59], while Jacquin-Courtois et al. showed that prism adaptation in patients with visual and auditory unilateral neglect could increase auditory responses on the side of neglect [60]. In other words, the effects of prism adaptation extended from the visual system to the auditory system. Musacchia et al. recently provided biological evidence that $\mathrm{HI}$ alone leads to degraded audiovisual (AV) integration abilities [61]. In their study, older adults with near-normal hearing and with mild-tomoderate hearing loss were presented with a synthetic syllable under auditory alone, visual alone, and AV conditions at a fixed sensation level. Peak P1 and N1 latencies and amplitudes were measured for each condition. The normal-hearing subjects showed significantly earlier latencies and subadditive P1 amplitudes in the AV condition over the auditory and visual conditions combined. The subjects with HI showed similar trends, but the differences were not significant. The authors concluded that this demonstrates diminished AV integration in individuals with HI. The implications of this for individuals with DSI are considerable in that it suggests the disadvantages over single sensory impairment will be multiplicative. Interestingly, the study of blast-exposed Veterans with 
TBI by Lew et al. showed that HI was the strongest predictor of VI, and vice versa, suggesting that these impairments may derive from a common source [19]. Studies to further elucidate these relationships and potential multiplicative effects are needed.

In sum, DSI affects many aspects of function: physical, psychological, and psychosocial. While substantially less is known about the functional effects of combined auditory and visual processing in blast-injured servicemembers and Veterans, they nevertheless represent critical considerations for the coordination of comprehensive and collaborative interdisciplinary care. The continuing paucity of research to clinically define DSI, develop clinical protocols for consistent and objective assessment, determine optimal approaches for rehabilitation, and develop integrated audiological and vision services represents a notable challenge to the field. These issues are further discussed later.

\section{Clinical Definition}

It is customary to classify medical disorders into degrees of severity. The value of such is that it provides a basic understanding of the activity limitations and participation restrictions an individual will encounter as a result of his or her impairment, it can help clinicians select appropriate interventions for the impairment, and it provides a metric from which to track change-either disease progression or improvement following intervention [62]. HI and VI are unfortunately, and problematically, diagnosed and treated in isolation [2]. HI is classified based on unaided ability to hear, while VI is classified using best-corrected vision. HIs are based primarily on threshold measures (pure-tone sensitivity), while definitions of VI center on the ability to resolve high-contrast spatial detail (acuity) and on visual fields. With this in mind, it is not surprising that a unified classification for DSI does not exist. In fact, the notion of conceptualizing DSI in an integrated and complimentary fashion, rather than as two distinct and independent phenomena incidentally presenting in the same individual, is relatively recent.

We acknowledge that developing a DSI classification system would be complex, since it would require an understanding of the relative effect of the two impairments. However, if achieved, this system would assist in the development of algorithms for selecting optimal interventions and rehabilitation strategies, so that, for instance, evidence-based decisions could be made regarding provision of differing interventions for someone with a mild HI coupled with severe VI versus someone with moderate HI and mild VI. A classification system of this sort would be prescriptive and thus would have to move from the traditional model of single-discipline definitions of sensory impairment reliant on hearing sensitivity and visual acuity indicators to integrated functional hearing and vision (dual sensory) assessments with demonstrated relevance to everyday functional capacities. Standardized tools to assess dual sensory function are prerequisite to moving to a system that provides comprehensive dual sensory care. Until such tools exist, a unified classification system is unlikely.

\section{Assessment}

As discussed earlier, assessment of sensory disorders is primarily focused on measurement of impairment (e.g., the extent to which thresholds change, the eardrum moves, and the eye can resolve high-contrast spatial detail). There are tools, such as tests of functional hearing (speech) or functional vision (reading), that assess the effects of sensory (dys)function on the everyday skills and abilities of the person, and there are questionnaires that measure perceived effects resulting from the functional limitations; however, these tools are less widely used in the clinic than those that measure impairment. To understand the effects of DSI and to target rehabilitation efforts, we propose the development of dual sensory assessment tools.

Evidence exists to suggest that blast injury causes damage to areas of the brain involved in auditory and visual processing. Tools for assessing central processing again focus on a single sense. There is also evidence that TBI can cause deficits in multisensory integration [63], such as limitations in the way the brain processes and combines information from each sense and the environment to assemble a unified picture, which might be noted in a task requiring the combination of auditory information with the articulatory gestures of the lips and face to improve recognition of speech in a noisy environment [64]. Successful multimodal integration results in responses to multimodal stimuli that are faster than would be predicted from response times to single-sensory stimuli [65] and that produce larger neural responses than single-sense inputs [66]. In its extreme, disrupted multisensory integration is thought to cause symptoms of autism-spectrum disorders [67] and schizophrenia [68], but in less extreme forms, it can manifest as learning difficulties; distractibility; impulsiveness; sensitivity to touch, sounds, and light; and abnormal activity levels (high or low). Many of these symptoms 
have been noted among blast-injured Veterans and are often attributed to PTSD. Tools to reliably differentiate PTSD from processing difficulties associated with mild TBI would be a valuable addition to the clinical battery. Toward this end, Peskind et al., using brain fluorodeoxyglucose positron emission tomography, reported that Veterans with mild TBI from multiple blast exposures had decreased cerebral metabolic rate of glucose in the cerebellum, vermis, pons, and medial temporal lobe, as well as subtle impairments in verbal fluency, cognitive processing speed, attention, and working memory, compared with 12 cognitively nondisabled volunteers from the community [69]. These deficits are similar to those seen in patients with cerebellar lesions and, thus, may indicate either a physical basis for PTSD or a method for differentiating PTSD from mild TBI.

Selection and development of assessment tools should be focused on those that measure activity limitations (i.e., difficulties that arise because of an impairment, such as an inability to hear speech clearly in a noisy location or to read a book in a dimly lit room) and participation restrictions (i.e., problems that arise from activity limitations, such as withdrawing from social activities). This approach differs from current practices of using unimodal tools that measure either hearing-specific or vision-specific function or performance. These tools would need to be equally sensitive to effect domains of auditory and visual dysfunction so as to comprehensively and realistically capture the functional sensory capacity of individuals with DSI in an integrated fashion. Given that uptake of information from our surroundings is not usually limited to one sensory modality, we hope that ecologically valid measures for assessing DSI in an integrated fashion will be developed. The availability of such tools is especially important for understanding the effects of DSI among blast-exposed Veterans, who often have little or no HI and/or VI as conventionally assessed and defined.

A number of performance-based tests of everyday function have been developed for assessment of activity limitations, for example, the Direct Assessment of Functional Status Scale [70], the Cognitive Performance Test [71], the Revised Observed Tasks of Daily Living [72], and Timed Instrumental Activities of Daily Living [73]. These tests require the participant to perform a number of everyday tasks using real-life materials in the laboratory or clinic. The participant's ability to perform each step of the task is scored. If such measures are to be used to assess DSI, it would be necessary to confirm that each is sensitive to HI alone and VI alone, as well as to DSI.
Unfortunately, none of these measures were developed with a single sensory impairment or DSI in mind, they are not standardized for use in clinical or rehabilitation settings, and there are no normative data available from large populations. Furthermore, the tasks are weighted toward use of vision more heavily than hearing; therefore, for assessment of DSI, those currently available would have to be considerably altered.

Self-report questionnaires or interviews are the most practical way to assess participation restrictions; indeed, there is growing consensus that assessment of daily function requires self-report measures as well as performancebased measures [74]. There are many sense-specific tools for evaluating the activity limitation and participation restrictions associated with $\mathrm{HI}$ and VI, such as the Abbreviated Profile of Hearing Aid Benefit [75], the Hearing Handicap Inventory for the Elderly [76], the Low Vision Visual Functioning Questionnaire [77], and the National Eye Institute Visual Functioning Questionnaire [78]. However, such questionnaires have limited utility for understanding the effects of DSI, since they focus on a single sensory impairment only. A questionnaire of potential utility for understanding the effects of DSI is the World Health Organization Disability Assessment Schedule II (WHODAS II), which provides a profile of functional abilities and effect of impairments in six domains: Understanding and Communicating, Getting Around, Self-Care, Getting Along with People, Life Activities, and Participation in Society. The WHO-DAS II was developed as a tool for identifying the needs of individuals with varying impairments, matching patients to interventions, tracking functioning over time, and measuring clinical outcomes and treatment effectiveness; thus, conceptually it is a highly appropriate tool for assessing DSI.

There is value in using both performance-based measures and self-report measures, because both have important strengths and weaknesses. Self-report measures are revealing because they provide the patient's perspective on, and personal experience of, the problem under investigation. On the other hand, self-report data are influenced by the patient's interpretation of questions, the accuracy of the patient's recall of information, the patient's emotional and psychological state (e.g., fatigue, motivation), and the patient's perception of what he or she believes the examiner wants to hear [79]. Correlations between degrees of reported and measured sensory loss are low [80], and discrepancies exist between selfreport and objective ratings [81-82]. Performance measures, on the other hand, avoid these issues, but they may 
lack construct validity and/or pertinence to a particular individual's lifestyle and daily activities. Furthermore, interventions yielding improvements in performance (particularly laboratory-based performances) but little or no change in self-perceived ability may be limited in terms of their potential for translation and integration into clinical practice (i.e., poor patient adherence or persistence due to limited perceived utility).

\section{Rehabilitation}

The major challenge for rehabilitation of DSI associated with blast injury is that traditional forms of rehabilitation for HI and VI (providing hearing aids and eyeglasses) are not applicable, because individuals tend to have normal to near-normal auditory and visual acuity. Indeed, the Veterans Health Administration (VHA) does not currently have established evidence-based approaches to rehabilitation for blast-related DSI associated with TBI. Current practices adopted by audiologists to address auditory difficulties include providing mild-gain hearing aids, personal FM systems, and auditory training programs [21]. There is good rationale for the use of each. Personal FM systems have been used successfully to manage auditory processing problems in children [83-84] and adults [85]. By placing the microphone of the FM close to the source of the wanted signal and then transmitting via radio frequency transmission to a receiver worn by the listener, there are significant improvements in the signal-to-noise ratio of speech in noisy and reverberant environments. It is believed that by enhancing the speech signal, more resources are made available for use in higher-level auditory processing. Auditory training has been shown to be successful for children with language learning disorders [86-87], for improving satisfaction and performance of adult hearing aid users [86-88], and for enhancing the memory of older adults [89]. An accumulating body of literature shows that auditory training has the potential to change neural function, as demonstrated by changes in electrophysiological metrics such as increased P300 amplitude and decreased latency to speech signals $[87,90]$ and changes in the amplitude and latencies of the N1-P2 complex [91-92]. Auditory training has also been shown to transfer from trained tasks to improved speech syllable identification [93], sentences in quiet [94] and in noise [88], high context sentences [95], and perceived hearing disability and handicap [88,95].

Rehabilitation practices commonly used by optometrists to address visual difficulties associated with blast injury and normal or near-normal visual acuity include refraction and the provision of optical interventions, including tints and filters to assist with photosensitivity and prisms to expand visual field, as well as nonoptical interventions, such as education regarding lighting, increasing contrast, and decreasing visual clutter. Vision therapy is used at times, most typically to address convergence insufficiency and accommodative infacility. Vision therapy, depending on the disorder(s) to be addressed, often requires at least 12 or more weekly or biweekly office therapy sessions that may be inconvenient, costly, and more time-consuming than home-based visual therapies. Stelmack et al. indicated that, in fact, spectacles were the primary (78\%) visual treatment prescribed for patients with TBI seen at one VA site in contrast with much lower provision of vision therapy (14\%) [37]. A recent national survey of VA optometrists specific to treatment of visual complaints in OIF/OEF Veterans showed that 84 percent provided spectacles, 61 percent provided prisms and filters, and 39 percent provided vision therapy; however, 16 percent indicated uncertainty as to the efficacy of their rehabilitation efforts in ameliorating their patients' deficits. A variety of training approaches have been applied to visual efficiency and visual information processing decrements in a variety of patient populations. Vision therapy protocols are a family of behavioral optometry approaches that address primarily visual efficiency anomalies in version, vergence, and accommodation and, to a lesser degree, in information processing disorders. Multicenter clinical trial-based evidence regarding efficacy, however, is limited, including specific to neurorehabilitation optometric approaches to the visual dysfunction seen in populations with TBI [9]. Nevertheless, a handful of studies suggest responsiveness of populations with TBI to training interventions. For instance, Freed and Hellerstein found that a small sample of patients with mild TBI receiving optometric rehabilitation that included vision therapy demonstrated greater visual system recovery based on visually evoked cortical potential testing than age-, sex-, and head size-matched controls [96]. Han et al. reported that computer-presented eye movement training resulted in improved reading-related eye movements, and this remediation was associated with decreased reports of reading dysfunction among adults with acquired brain injury, including those with TBI [97]. Similarly, brainplasticity grounded vision restoration training of residual visual function has resulted in visual field (re)expansion [98]. Practice-related improvements in the functional or 
useful field of view in nondisabled adults is thought to result from enhancements in visual perceptual processing and attention, including speed, identification, discrimination, and attention abilities [99-100]. These studies demonstrate that visual training can improve visual function associated with visual processing deficits, and investigators such as Scalf et al. present neuroimaging data elucidating the neural correlates of these improvements [99].

It is conceivable that devices can be developed that use incoming visual and auditory inputs to enhance visual and auditory cues or that tactile information be collected to enhance limited auditory and visual input. Such approaches would potentially enhance multisensory integration processes. A system of this nature is being developed by Jacobs et al. at the National Center for Rehabilitative Auditory Research (Portland, Oregon), in which mutual information obtained from a camera focused on the face of a speaker will be combined with that obtained by a hearing aid in the ear of the listener [101]. Using sophisticated algorithms, these data can be used to extract signal from noise and, thus, to attenuate the noise and improve the signal-to-noise ratio. Crossdisciplinary development of new patient-centered technologies is crucial for optimal development of new devices for DSI.

The goal of cross-disciplinary rehabilitation is to address DSI within the context of the whole individual, taking into account the DSI as well as other co-impairments so that strategies to optimize residual capacities, accommodate losses, and teach compensatory strategies can be devised. Accordingly, rehabilitation efforts will entail tailoring environmental and technologic and training and/or retraining rehabilitative interventions to maximize functional independence. Innovative, integrative, and new models of assessment and care are needed. Educating emerging and future audiology and vision providers in multisensory team-based processes of care is a critical first step.

The ultimate goal of rehabilitation is to restore full participation in society and quality of life and ensure individuals have the full capacity to participate in education, vocation, independent living, social activities, relationships, and recreation. While quality of life is often considered in assessment of outcomes, reintegration is rarely assessed. According to the VHA Handbook (1172.04), reintegration is the resumption of age, sex, and culturally appropriate roles in the family community and workplace. In a meta-analytic evaluation of the methodological quality of research on cognitive rehabilitation after TBI, Cicerone et al. reported that of 32 randomized clinical trials, only 4 measured treatment effects on participation and only 1 on quality of life [102]. Given the prevalence of DSI in blast-exposed Veterans, evidence for impaired community integration following TBI [103], and the challenges that vision and hearing difficulties pose in everyday life [2], assessment of reintegration and quality of life in returning OIF/OEF servicemembers should be considered critical metrics when VA is evaluating the success of its rehabilitation programs. This is because while performance-based assessments, such as reading and speech discrimination, are clearly important to everyday function, they do not necessarily capture patient-centered outcomes, such as return to job, activity, and independent living and life satisfaction overall.

\section{CONCLUSIONS}

Providers are faced with numerous challenges regarding blast-related DSI that include definition of the problem, quantification and assessment of its effects, selection of rehabilitation strategies, and the development of a service-provision model. Further, awareness of DSI resulting from blast-exposure is relatively recent, and thus, it is not known whether the limited knowledge about DSI in the aging population is even applicable to this younger population of Veterans whose reported functional difficulties are similar but whose DSI etiology, reserve capacities, lifestyle, and needs are quite different.

We recommend the assessment and rehabilitation approach to blast-related DSI depicted in the Figure and emphasize the necessity of engaging in an interdisciplinary team-based approach to rehabilitation. The model depicted in the Figure uses the International Classification of Functioning, Disability and Health [104], which shifts the focus from causes to effects along a common metric of health and disability, to guide assessment, classification, and rehabilitation and to illustrate the interrelationships between them. Specifically, blast injuries to brain, ears, eyes, and other parts of the body lead to HIs and VIs. The severity of these injuries depends on a number of variables, including blast intensity and number of exposures. In blast-related DSI, visual and auditory processing are affected and relative degree of these processing impairments directly influences functional vision and hearing performance. Functional vision and hearing effects manifest as activity limitations and participation restrictions, which will impair reintegration, recovery, 


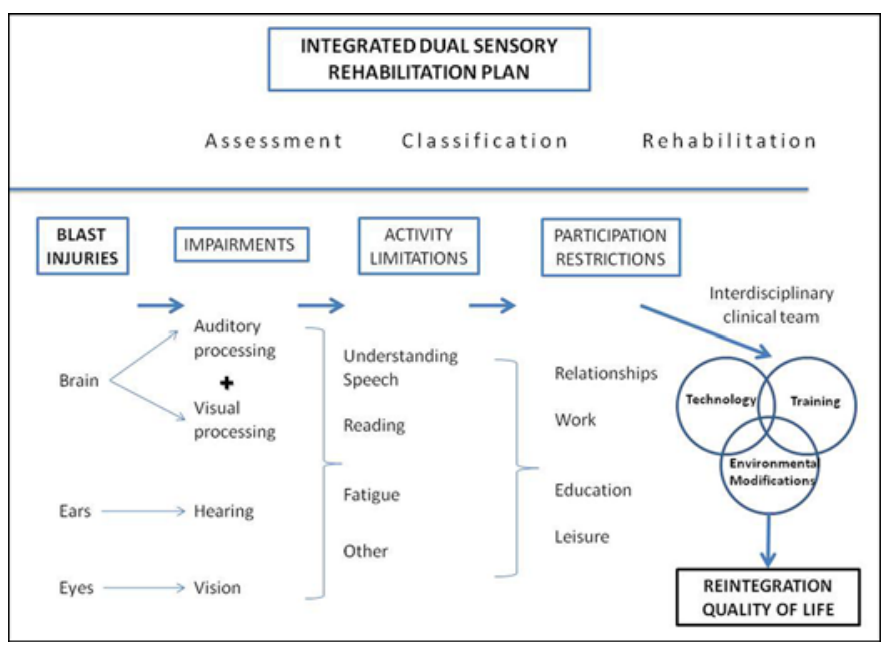

Figure.

Flow diagram depicting our recommended approach to assessment and rehabilitation of blast-related dual sensory impairment.

and quality of life. An interdisciplinary clinical team approach to rehabilitation that incorporates technology, vision and auditory training, and environmental modifications to accommodate and compensate for impairments is thus necessary to optimize societal reintegration and attainment of preinjury quality of life.

\section{ACKNOWLEDGMENTS}

\section{Author Contributions:}

Study concept and design: G. H. Saunders, K. V. Echt.

Drafting of manuscript: G. H. Saunders, K. V. Echt.

Critical revision of manuscript for important intellectual content:

G. H. Saunders, K. V. Echt.

Financial Contributions: The authors have declared that no competing interests exist.

Funding/Support: This material is based on work supported by the VA Rehabilitation Research and Development Service (grants 4844C and C4850C).

Additional Contributions: The authors would like to thank Terri Pogoda, PhD, for her valuable input on an earlier version of the manuscript.

Disclaimer: The contents of this article do not necessarily represent the views of the VA or the U.S. Government.

\section{REFERENCES}

1. Rönnberg J, Borg E. A review and evaluation of research on the deaf-blind from perceptual, communicative, social and rehabilitative perspectives. Scand Audiol. 2001;
30(2):67-77. [PMID:11409790]

http://dx.doi.org/10.1080/010503901300112176

2. Saunders GH, Echt KV. An overview of dual sensory impairment in older adults: perspectives for rehabilitation. Trends Amplif. 2007;11(4):243-58. [PMID:18003868] http://dx.doi.org/10.1177/1084713807308365

3. Gondusky JS, Reiter MP. Protecting military convoys in Iraq: an examination of battle injuries sustained by a mechanized battalion during Operation Iraqi Freedom II. Mil Med. 2005;170(6):546-49. [PMID:16001610]

4. Fausti SA, Wilmington DJ, Gallun FJ, Myers PJ, Henry JA. Auditory and vestibular dysfunction associated with blast-related traumatic brain injury. J Rehabil Res Dev. 2009;46(6):797-810. [PMID:20104403] http://dx.doi.org/10.1682/JRRD.2008.09.0118

5. Padula W, Ikeda E, Fong D, Vicci V. The need for optometric rehabilitation for our veterans who have incurred a traumatic brain injury-Senate Bill 1999/House Bill 3558. Optometry. 2008;79(4):170-71. [PMID:18358995] http://dx.doi.org/10.1016/j.optm.2008.02.003

6. Gallun F, Leek M, Diedesch A, Henry J, Saunders G, Fausti S, et al. Understanding and addressing the effects of blast exposure on the auditory system. Ongoing studies at the National Center for Rehabilitative Auditory Research. Annual VA Rehabilitation Research and Development Centers of Excellence Directors' and Administrative Officers' Meeting; 2010 May 25-26; Pittsburg, PA.

7. Cockerham GC, Goodrich GL, Weichel ED, Orcutt JC, Rizzo JF, Bower KS, Schuchard RA. Eye and visual function in traumatic brain injury. J Rehabil Res Dev. 2009; 46(6):811-18. [PMID:20104404] http://dx.doi.org/10.1682/JRRD.2008.08.0109

8. Myers P. Patterns of auditory dysfunction and TBI. NCRAR Pre-conference Workshop: Current Directions and Interdisciplinary Approaches to mTBI; 2009 Oct 7; Portland, OR.

9. Kapoor N, Ciuffreda KJ. Vision disturbances following traumatic brain injury. Curr Treat Options Neurol. 2002; 4(4):271-80. [PMID:12036500] http://dx.doi.org/10.1007/s11940-002-0027-z

10. Lew HL, Weihing J, Myers PJ, Pogoda TK, Goodrich GL. Dual sensory impairment (DSI) in traumatic brain injury (TBI)-An emerging interdisciplinary challenge. NeuroRehabilitation. 2010;26(3):213-22. [PMID:20448311]

11. Warden D. Military TBI during the Iraq and Afghanistan wars. J Head Trauma Rehabil. 2006;21(5):398-402. [PMID:16983225] http://dx.doi.org/10.1097/00001199-200609000-00004

12. Okie S. Traumatic brain injury in the war zone. N Engl J Med. 2005;352(20):2043-47. [PMID:15901856] http://dx.doi.org/10.1056/NEJMp058102 
13. DePalma RG, Burris DG, Champion HR, Hodgson MJ. Blast injuries. N Engl J Med. 2005;352(13):1335-42. [PMID:15800229] http://dx.doi.org/10.1056/NEJMra042083

14. Taber KH, Warden DL, Hurley RA. Blast-related traumatic brain injury: what is known? J Neuropsychiatry Clin Neurosci. 2006;18(2):141-45. [PMID:16720789]

15. Dikmen SS, Machamer JE, Winn HR, Temkin NR. Neuropsychological outcome at 1-year post head injury. Neuropsychology. 1995;9(1):80-90. http://dx.doi.org/10.1037/0894-4105.9.1.80

16. Kerr AG, Byrne JE. Surgery of violence. IV. Blast injuries of the ear. BMJ. 1975;1(5957):559-61. [PMID:1139149] http://dx.doi.org/10.1136/bmj.1.5957.559

17. Cave KM, Cornish EM, Chandler DW. Blast injury of the ear: clinical update from the Global War on Terror. Mil Med. 2007;172(7):726-30. [PMID:17691685]

18. Lew HL, Jerger JF, Guillory SB, Henry JA. Auditory dysfunction in traumatic brain injury. J Rehabil Res Dev. 2007;44(7):921-28. [PMID:18075949] http://dx.doi.org/10.1682/JRRD.2007.09.0140

19. Lew HL, Pogoda TK, Baker E, Stolzmann KL, Meterko M, Cifu DX, Amara J, Hendricks AM. Prevalence of dual sensory impairment and its association with traumatic brain injury and blast exposure in OEF/OIF veterans. J Head Trauma Rehabil. 2011;26(6):489-96.

[PMID:21386715] http://dx.doi.org/10.1097/HTR.0b013e318204e54b

20. Chandler DW. Blast-related ear injury in current U.S. military operations. ASHA Leader. 2006;11:9-26.

21. Saunders G, Abrams H. Evaluation of approaches to auditory rehabilitation of mTBI. NCRAR Pre-conference Workshop: Current Directions and Interdisciplinary Approaches to mTBI; 2009 Oct 7; Portland, OR.

22. Gallun FJ, Diedesch AC, Kubli LR, Walden TC, Folmer RL, Lewis MS, McDermott DJ, Fausti SA, Leek MR. Performance on tests of central auditory processing by individuals exposed to high-intensity blasts. J Rehabil Res Dev. 2012;49(7):1005-24.

http://dx.doi.org/10.1682/JRRD.2012.03.0038

23. Bamiou DE, Musiek FE, Stow I, Stevens J, Cipolotti L, Brown MM, Luxon LM. Auditory temporal processing deficits in patients with insular stroke. Neurology. 2006; 67(4):614-19. [PMID:16924014] http://dx.doi.org/10.1212/01.wnl.0000230197.40410.db

24. Griffiths TD, Rees A, Witton C, Cross PM, Shakir RA, Green GG. Spatial and temporal auditory processing deficits following right hemisphere infarction. A psychophysical study. Brain. 1997;120(Pt 5):785-94.

[PMID:9183249]

http://dx.doi.org/10.1093/brain/120.5.785

25. Paré N, Rabin LA, Fogel J, Pépin M. Mild traumatic brain injury and its sequelae: characterisation of divided atten- tion deficits. Neuropsychol Rehabil. 2009;19(1):110-37. [PMID:18609010] http://dx.doi.org/10.1080/09602010802106486

26. Kwok FY, Lee TM, Leung CH, Poon WS. Changes of cognitive functioning following mild traumatic brain injury over a 3-month period. Brain Inj. 2008;22(10):740-51. [PMID:18787983] http://dx.doi.org/10.1080/02699050802336989

27. Lew HL, Lee EH, Pan SS, Date ES. Electrophysiologic abnormalities of auditory and visual information processing in patients with traumatic brain injury. Am J Phys Med Rehabil. 2004;83(6):428-33. [PMID:15166686] http://dx.doi.org/10.1097/00002060-200406000-00004

28. Segalowitz SJ, Bernstein DM, Lawson S. P300 eventrelated potential decrements in well-functioning university students with mild head injury. Brain Cogn. 2001; 45(3):342-56. [PMID:11305878] http://dx.doi.org/10.1006/brcg.2000.1263

29. Gaetz M, Weinberg H. Electrophysiological indices of persistent post-concussion symptoms. Brain Inj. 2000; 14(9):815-32. [PMID:11030455] http://dx.doi.org/10.1080/026990500421921

30. Lew HL, Poole JH, Vanderploeg RD, Goodrich GL, Dekelboum S, Guillory SB, Sigford B, Cifu DX. Program development and defining characteristics of returning military in a VA Polytrauma Network Site. J Rehabil Res Dev. 2007;44(7):1027-34. [PMID:18075959] http://dx.doi.org/10.1682/JRRD.2007.05.0073

31. Stelmack J. Hines multidisciplinary team: Vision research. National VHA/DOD Conference: Sensory Impairment Issues in Traumatic Brain Injury; 2009 Dec 8-10; Chicago, IL.

32. Hills EC, Geldmacher DS. The effect of character and array type on visual spatial search quality following traumatic brain injury. Brain Inj. 1998;12(1):69-76. [PMID:9483339] http://dx.doi.org/10.1080/026990598122872

33. Novack TA, Baños JH, Alderson AL, Schneider JJ, Weed W, Blankenship J, Salisbury D. UFOV performance and driving ability following traumatic brain injury. Brain Inj. 2006;20(5):455-61. [PMID:16716991] http://dx.doi.org/10.1080/02699050600664541

34. Sayer NA, Chiros CE, Sigford B, Scott S, Clothier B, Pickett T, Lew HL. Characteristics and rehabilitation outcomes among patients with blast and other injuries sustained during the Global War on Terror. Arch Phys Med Rehabil. 2008;89(1):163-70. [PMID:18164349] http://dx.doi.org/10.1016/j.apmr.2007.05.025

35. Kapoor N, Ciuffreda K. Vision deficits following acquired brain injury. In: Cristian A, editor. Medical management of adults with neurologic disabilities. New York (NY): Demos Medical Publishing; 2009. p. 407-23.

36. Goodrich GL, Kirby J, Cockerham G, Ingalla SP, Lew HL. Visual function in patients of a polytrauma rehabilitation 
center: A descriptive study. J Rehabil Res Dev. 2007; 44(7):929-36. [PMID:18075950]

http://dx.doi.org/10.1682/JRRD.2007.01.0003

37. Stelmack JA, Frith T, Van Koevering D, Rinne S, Stelmack TR. Visual function in patients followed at a Veterans Affairs Polytrauma Network Site: an electronic medical record review. Optometry. 2009;80(8):419-24.

[PMID:19635432]

http://dx.doi.org/10.1016/j.optm.2009.02.011

38. World Health Organization. Fact sheet no. 282: Magnitude and causes of visual impairment. Geneva (Switzerland): World Health Organization; 2006.

39. International Council of Ophthalmology (ICO). Visual standards-Aspects and ranges of vision loss. 29th International Congress of Ophthalmology; 2002; Sydney, Australia.

40. Lupsakko TA, Mäntyjärvi MI, Sulkava RO, Kautiainen HJ. Combined functional visual and hearing impairment in a population aged 75 and older in Finland and its influence on activities of daily living. J Am Geriatr Soc. 2002; 50(10):1748-49. [PMID:12366637] http://dx.doi.org/10.1046/j.1532-5415.2002.50476.x

41. Campbell VA, Crews JE, Moriarty DG, Zack MM, Blackman DK. Surveillance for sensory impairment, activity limitation, and health-related quality of life among older adults-United States, 1993-1997. MMWR CDC Surveill Summ. 1999;48(8):131-56. [PMID:10634273]

42. Caban AJ, Lee DJ, Gómez-Marín O, Lam BL, Zheng DD. Prevalence of concurrent hearing and visual impairment in US adults: The National Health Interview Survey, 1997-2002. Am J Public Health. 2005;95(11):1940-42. [PMID:16195516] http://dx.doi.org/10.2105/AJPH.2004.056671

43. Brennan M, Su YP, Horowitz A. Longitudinal associations between dual sensory impairment and everyday competence among older adults. J Rehabil Res Dev. 2006; 43(6):777-92. [PMID:17310427] http://dx.doi.org/10.1682/JRRD.2005.06.0109

44. Smith SL, Bennett LW, Wilson RH. Prevalence and characteristics of dual sensory impairment (hearing and vision) in a veteran population. J Rehabil Res Dev. 2008; 45(4):597-609. [PMID:18712645] http://dx.doi.org/10.1682/JRRD.2007.02.0023

45. Lew HL, Garvert DW, Pogoda TK, Hsu PT, Devine JM, White DK, Myers PJ, Goodrich GL. Auditory and visual impairments in patients with blast-related traumatic brain injury: Effect of dual sensory impairment on Functional Independence Measure. J Rehabil Res Dev. 2009;46(6): 819-26. [PMID:20104405] http://dx.doi.org/10.1682/JRRD.2008.09.0129

46. Brahm KD, Wilgenburg HM, Kirby J, Ingalla S, Chang CY, Goodrich GL. Visual impairment and dysfunction in combat-injured servicemembers with traumatic brain injury. Optom Vis Sci. 2009;86(7):817-25. [PMID:19521270]

http://dx.doi.org/10.1097/OPX.0b013e3181adff2d

47. Crews JE, Campbell VA. Vision impairment and hearing loss among community-dwelling older Americans: implications for health and functioning. Am J Public Health. 2004;94(5):823-29. [PMID:15117707] http://dx.doi.org/10.2105/AJPH.94.5.823

48. Raina $\mathrm{P}$, Wong $\mathrm{M}$, Massfeller $\mathrm{H}$. The relationship between sensory impairment and functional independence among elderly. BMC Geriatr. 2004;4(1):3-11. [PMID:15132757] http://dx.doi.org/10.1186/1471-2318-4-3

49. Chou K-L, Chi I. Combined effect of vision and hearing impairment on depression in elderly Chinese. Int J Geriatr Psychiatry. 2004;19(9):825-32. [PMID:15352139] http://dx.doi.org/10.1002/gps.1174

50. Chia EM, Mitchell P, Rochtchina E, Foran S, Golding M, Wang JJ. Association between vision and hearing impairments and their combined effects on quality of life. Arch Ophthalmol. 2006;124(10):1465-70. [PMID:17030715] http://dx.doi.org/10.1001/archopht.124.10.1465

51. Sumby W, Pollack I. Visual contribution to speech intelligibility in noise. J Acoust Soc Am. 1954;26:212-15. http://dx.doi.org/10.1121/1.1907309

52. Erber NP. Auditory-visual perception of speech. J Speech Hear Disord. 1975;40(4):481-92. [PMID:1234963]

53. Walden BE, Busacco DA, Montgomery AA. Benefit from visual cues in auditory-visual speech recognition by middle-aged and elderly persons. J Speech Hear Res. 1993;36(2):431-36. [PMID:8487533]

54. Summerfield A. Some preliminaries to a comprehensive account of audio-visual speech perception. In: Dodd B, Campbell R, editors. Hearing by eye: The psychology of lipreading. Hillsdale (NJ): Lawrence Erlbaum Associates; 1987. p. 3-51.

55. Grant KW, Walden BE, Seitz PF. Auditory-visual speech recognition by hearing-impaired subjects: consonant recognition, sentence recognition, and auditory-visual integration. J Acoust Soc Am. 1998;103(5 Pt 1):2677-90. [PMID:9604361] http://dx.doi.org/10.1121/1.422788

56. Walden BE, Grant KW, Cord MT. Effects of amplification and speechreading on consonant recognition by persons with impaired hearing. Ear Hear. 2001;22(4):333-41. [PMID:11527039] http://dx.doi.org/10.1097/00003446-200108000-00007

57. Cappe C, Barone P. Heteromodal connections supporting multisensory integration at low levels of cortical processing in the monkey. Eur J Neurosci. 2005;22(11):28862902. [PMID:16324124] http://dx.doi.org/10.1111/j.1460-9568.2005.04462.x 
58. Wang Y, Celebrini S, Trotter Y, Barone P. Visuo-auditory interactions in the primary visual cortex of the behaving monkey: electrophysiological evidence. BMC Neurosci. 2008;9:79. [PMID:18699988]

http://dx.doi.org/10.1186/1471-2202-9-79

59. Recanzone GH. Rapidly induced auditory plasticity: the ventriloquism aftereffect. Proc Natl Acad Sci USA. 1998; 95(3):869-75. [PMID:9448253] http://dx.doi.org/10.1073/pnas.95.3.869

60. Jacquin-Courtois S, Rode G, Pavani F, O’Shea J, Giard $\mathrm{MH}$, Boisson D, Rossetti Y. Effect of prism adaptation on left dichotic listening deficit in neglect patients: glasses to hear better? Brain. 2010;133(Pt 3):895-908.

[PMID:20110244]

http://dx.doi.org/10.1093/brain/awp327

61. Musacchia G, Arum L, Nicol T, Garstecki D, Kraus N. Audiovisual deficits in older adults with hearing loss: biological evidence. Ear Hear. 2009;30(5):505-14.

[PMID:19546807] http://dx.doi.org/10.1097/AUD.0b013e3181a7f5b7

62. Stucki G, Ewert T, Cieza A. Value and application of the ICF in rehabilitation medicine. Disabil Rehabil. 2002; 24(17):932-38. [PMID:12523361] http://dx.doi.org/10.1080/09638280210148594

63. Sarno S, Erasmus LP, Lipp B, Schlaegel W. Multisensory integration after traumatic brain injury: a reaction time study between pairings of vision, touch and audition. Brain Inj. 2003;17(5):413-26. [PMID:12745713] http://dx.doi.org/10.1080/0269905031000070161

64. Eramudugolla R, Henderson R, Mattingley JB. Effects of audio-visual integration on the detection of masked speech and non-speech sounds. Brain Cogn. 2011;75(1): 60-66. [PMID:21067852] http://dx.doi.org/10.1016/j.bandc.2010.09.005

65. Giard MH, Peronnet F. Auditory-visual integration during multimodal object recognition in humans: a behavioral and electrophysiological study. J Cogn Neurosci. 1999; 11(5):473-90. [PMID:10511637] http://dx.doi.org/10.1162/089892999563544

66. Macaluso E, Frith CD, Driver J. Modulation of human visual cortex by crossmodal spatial attention. Science. 2000; 289(5482):1206-8. [PMID:10947990] http://dx.doi.org/10.1126/science.289.5482.1206

67. Oberman LM, Ramachandran VS. Preliminary evidence for deficits in multisensory integration in autism spectrum disorders: the mirror neuron hypothesis. Soc Neurosci. 2008;3(3-4):348-55. [PMID:18979385] http://dx.doi.org/10.1080/17470910701563681

68. De Gelder B, Vroomen J, de Jong SJ, Masthoff ED, Trompenaars FJ, Hodiamont P. Multisensory integration of emotional faces and voices in schizophrenics. Schizophr Res. 2005;72(2-3):195-203. [PMID:15560964] http://dx.doi.org/10.1016/j.schres.2004.02.013
69. Peskind ER, Petrie EC, Cross DJ, Pagulayan K, McCraw K, Hoff D, Hart K, Yu CE, Raskind MA, Cook DG, Minoshima S. Cerebrocerebellar hypometabolism associated with repetitive blast exposure mild traumatic brain injury in 12 Iraq war Veterans with persistent post-concussive symptoms. Neuroimage. 2011;54(Suppl 1):S76-82. [PMID:20385245] http://dx.doi.org/10.1016/j.neuroimage.2010.04.008

70. Zanetti O, Frisoni GB, Rozzini L, Bianchetti A, Trabucchi M. Validity of direct assessment of functional status as a tool for measuring Alzheimer's disease severity. Age Ageing. 1998;27(5):615-22. [PMID:12675100] http://dx.doi.org/10.1093/ageing/27.5.615

71. Burns T, Mortimer JA, Merchak P. Cognitive Performance Test: a new approach to functional assessment in Alzheimer's disease. J Geriatr Psychiatry Neurol. 1994; 7(1):46-54. [PMID:8192830]

72. Diehl M, Marsiske M, Horgas AL, Rosenberg A, Saczynski JS, Willis SL. The Revised Observed Tasks of Daily Living: A performance-based assessment of everyday problem solving in older adults. J Appl Gerontol. 2005; 24(3):211-30. [PMID:18160968] http://dx.doi.org/10.1177/0733464804273772

73. Owsley C, McGwin G Jr, Sloane ME, Stalvey BT, Wells J. Timed instrumental activities of daily living tasks: relationship to visual function in older adults. Optom Vis Sci. 2001;78(5):350-59. [PMID:11384013] http://dx.doi.org/10.1097/00006324-200105000-00019

74. Allaire JC, Marsiske M. Everyday cognition: age and intellectual ability correlates. Psychol Aging. 1999;14(4): 627-44. [PMID:10632150] http://dx.doi.org/10.1037/0882-7974.14.4.627

75. Cox RM, Alexander GC. The abbreviated profile of hearing aid benefit. Ear Hear. 1995;16(2):176-86. [PMID:7789669] http://dx.doi.org/10.1097/00003446-199504000-00005

76. Ventry IM, Weinstein BE. The hearing handicap inventory for the elderly: a new tool. Ear Hear. 1982;3(3):128-34. [PMID:7095321] http://dx.doi.org/10.1097/00003446-198205000-00006

77. Stelmack JA, Szlyk JP, Stelmack TR, Demers-Turco P, Williams RT, Moran D, Massof RW. Measuring outcomes of vision rehabilitation with the Veterans Affairs Low Vision Visual Functioning Questionnaire. Invest Ophthalmol Vis Sci. 2006;47(8):3253-61. [PMID:16877389] http://dx.doi.org/10.1167/iovs.05-1319

78. Mangione CM, Lee PP, Gutierrez PR, Spritzer K, Berry S, Hays RD; National Eye Institute Visual Function Questionnaire Field Test Investigators. Development of the 25item National Eye Institute Visual Function Questionnaire. Arch Ophthalmol. 2001;119(7):1050-58. [PMID:11448327] 
79. Kempken GI, Steverink N, Ormel J, Deeg DJ. The assessment of ADL among frail elderly in an interview survey: Self-report versus performance-based tests and determinants of discrepancies. J Gerontol B Psychol Sci Soc Sci. 1996;51(5):P254-60. [PMID:8809001]

http://dx.doi.org/10.1093/geronb/51B.5.P254

80. Reuben DB, Mui S, Damesyn M, Moore AA, Greendale GA. The prognostic value of sensory impairment in older persons. J Am Geriatr Soc. 1999;47(8):930-35. [PMID:10443852]

81. Shulman LM, Pretzer-Aboff I, Anderson KE, Stevenson R, Vaughan CG, Gruber-Baldini AL, Reich SG, Weiner WJ. Subjective report versus objective measurement of activities of daily living in Parkinson's disease. Mov Disord. 2006;21(6):794-99. [PMID:16482533] http://dx.doi.org/10.1002/mds.20803

82. Saunders GH, Forsline A. The Performance-Perceptual Test (PPT) and its relationship to aided reported handicap and hearing aid satisfaction. Ear Hear. 2006;27(3):229-42. [PMID:16672792] http://dx.doi.org/10.1097/01.aud.0000215976.64444.e6

83. Friederichs E, Friederichs P. Electrophysiologic and psycho-acoustic findings following one-year application of a personal ear-level FM device in children with attention deficit and suspected central auditory processing disorder. J Educ Audiol. 2005;12:31-36.

84. Phonak Hearing Systems. Edulink: Improves speech understanding in noisy classrooms. Field Study News. 2004 May.

85. Stach BA, Loisell LH, Jerger JF, Mintz SL, Taylor C. Clinical experience with personal FM assistive listening devices. Hear J. 1987;40:24-30.

86. Hayes EA, Warrier CM, Nicol TG, Zecker SG, Kraus N. Neural plasticity following auditory training in children with learning problems. Clin Neurophysiol. 2003;114(4): 673-84. [PMID:12686276] http://dx.doi.org/10.1016/S1388-2457(02)00414-5

87. Gil D, Iorio MC. Formal auditory training in adult hearing aid users. Clinics. 2010;65(2):165-74. [PMID:20186300] http://dx.doi.org/10.1590/S1807-59322010000200008

88. Sweetow RW, Sabes JH. The need for and development of an adaptive Listening and Communication Enhancement (LACE) Program. J Am Acad Audiol. 2006;17(8):538-58. [PMID:16999250] http://dx.doi.org/10.3766/jaaa.17.8.2

89. Mahncke HW, Connor BB, Appelman J, Ahsanuddin ON, Hardy JL, Wood RA, Joyce NM, Boniske T, Atkins SM, Merzenich MM. Memory enhancement in healthy older adults using a brain plasticity-based training program: a randomized, controlled study. Proc Natl Acad Sci U S A. 2006;103(33):12523-28. [PMID:16888038] http://dx.doi.org/10.1073/pnas.0605194103
90. Warrier CM, Johnson KL, Hayes EA, Nicol T, Kraus N. Learning impaired children exhibit timing deficits and training-related improvements in auditory cortical responses to speech in noise. Exp Brain Res. 2004;157(4): 431-41. [PMID:15067434] http://dx.doi.org/10.1007/s00221-004-1857-6

91. Tremblay KL, Shahin AJ, Picton T, Ross B. Auditory training alters the physiological detection of stimulusspecific cues in humans. Clin Neurophysiol. 2009;120(1): 128-35. [PMID:19028139] http://dx.doi.org/10.1016/j.clinph.2008.10.005

92. Reinke KS, He Y, Wang C, Alain C. Perceptual learning modulates sensory evoked response during vowel segregation. Brain Res Cogn Brain Res. 2003;17(3):781-91. [PMID:14561463] http://dx.doi.org/10.1016/S0926-6410(03)00202-7

93. Stecker GC, Bowman GA, Yund EW, Herron TJ, Roup CM, Woods DL. Perceptual training improves syllable identification in new and experienced hearing aid users. J Rehabil Res Dev. 2006;43(4):537-52. [PMID:17123192] http://dx.doi.org/10.1682/JRRD.2005.11.0171

94. Humes LE, Burk MH, Strauser LE, Kinney DL. Development and efficacy of a frequent-word auditory training protocol for older adults with impaired hearing. Ear Hear. 2009;30(5):613-27. [PMID:19633564] http://dx.doi.org/10.1097/AUD.0b013e3181b00d90

95. Chisolm T, McArdle R, Saunders G, Smith S, Wilson R. Efficacy of auditory training for adults: Preliminary results. International Conference on Adult Hearing Screening; 2010 Jun 10-12; Como Lake, Italy.

96. Freed S, Hellerstein LF. Visual electrodiagnostic findings in mild traumatic brain injury. Brain Inj. 1997;11(1):25-36. [PMID:9012549] http://dx.doi.org/10.1080/026990597123782

97. Han Y, Ciuffreda KJ, Kapoor N. Reading-related oculomotor testing and training protocols for acquired brain injury in humans. Brain Res Brain Res Protoc. 2004; 14(1):1-12. [PMID:15519946] http://dx.doi.org/10.1016/j.brainresprot.2004.06.002

98. Sabel BA, Kasten E. Restoration of vision by training of residual functions. Curr Opin Ophthalmol. 2000;11(6): 430-36. [PMID:11141637] http://dx.doi.org/10.1097/00055735-200012000-00008

99. Scalf PE, Colcombe SJ, McCarley JS, Erickson KI, Alvarado M, Kim JS, Wadhwa RP, Kramer AF. The neural correlates of an expanded functional field of view. J Gerontol B Psychol Sci Sco Sci. 2007;62 Spec No 1:3244.

[PMID:17565163] http://dx.doi.org/10.1093/geronb/62.special issue 1.32

100. Ball K, Berch DB, Helmers KF, Jobe JB, Leveck MD, Marsiske M, Morris JN, Rebok GW, Smith DM, Tennstedt SL, 
Unverzagt FW, Willis SL; Advanced Cognitive Training for Independent and Vital Elderly Study Group. Effects of cognitive training interventions with older adults: a randomized controlled trial. JAMA. 2002;288(18):2271-81. [PMID:12425704] http://dx.doi.org/10.1001/jama.288.18.2271

101. Jacobs PG, Erdogmus D, Saunders GH. Methods on improving signal-to-noise ratio of a speech signal using visual features from a speaker's face. International Hearing Aid Conference; 2012 Aug 8-12; Lake Tahoe, CA.

102. Cicerone KD, Azulay J, Trott C. Methodological quality of research on cognitive rehabilitation after traumatic brain injury. Arch Phys Med Rehabil. 2009;90(11 Suppl):S52-59. [PMID:19892075]

http://dx.doi.org/10.1016/j.apmr.2009.05.019

103. Sander AM, Clark A, Pappadis MR. What is community integration anyway?: defining meaning following traumatic brain injury. J Head Trauma Rehabil. 2010;25(2): 121-27. [PMID:20134333] http://dx.doi.org/10.1097/HTR.0b013e3181cd1635
104. World Health Organization. International Classification of Functioning, Disability and Health: ICF. Geneva (Switzerland): World Health Organization; 2001.

Submitted for publication August 20, 2010. Accepted in revised form May 3, 2011.

This article and any supplementary material should be cited as follows:

Saunders GH, Echt KV. Blast exposure and dual sensory impairment: An evidence review and integrated rehabilitation approach. J Rehabil Res Dev. 2012;49(7):1043-58. http://dx.doi.org/10.1682/JRRD.2010.08.0157

ResearcherID: Gabrielle H. Saunders, PhD: F-4768-2012

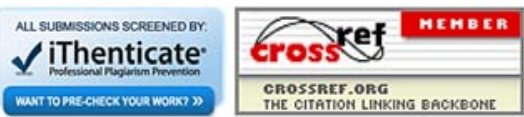

